\title{
Project Failure Case Studies and Suggestion
}

\author{
Nilofur Abbasi \\ M.phill Business \\ Administration, \\ Kinnaird College \\ Lahore, Pakistan
}

\author{
Iqra Wajid \\ M.phill Business \\ Administration, \\ Kinnaird College \\ Lahore, Pakistan
}

\author{
Zahra lqbal \\ M.phill Business \\ Administration, \\ Kinnaird College \\ Lahore, Pakistan
}

\author{
Fareeha Zafar, \\ Ph.D \\ University of Derby, \\ Currently Working in \\ Govt. College \\ University Lahore \\ Pakistan
}

\begin{abstract}
In this research paper three different case studies are taken under consideration. Step by step all three cases are described. These cases are about projects which had to face failure. Therefore, the reasons for failure of projects are identified and recommendations are given to ail failing projects.

First case study is about British Petroleum which is oil and Gas Company had to face situation which was not just critical but new for any oil company. The incident occurred due to explosion in the deep-water horizon while BP technical staff was trying to drill a well. Moreover, BP was not able to stop oil flow for three months.

Second case is about Chrysler and Fiat. Both were automobile companies and had to face failure. Marchionne was the one who saved both companies. The main focus of this case is merger of these two companies and the challenges faced by CEO due to organizational change after merger.

Third case study is about Millennium Dome, one of the controversial projects in the history of construction projects because of number of reasons. With the help of case study we will be able to learn the causes of failure of this project. Further recommendations to ail failure are given.
\end{abstract}

\section{Key Words}

Project Failure, British Petroleum, Chrysler and Fiat, Millennium Dome, Success.

\section{INTRODUCTION}

Before we start focusing on the main topic, it is vital to clearly understand some core terms/definitions.

\section{PROJECT}

A project is a mode of organizing resource. It is a group of individuals who are assembled to execute different tasks on a familiar set of objectives for a distinct period of time. Projects need a leader who can identify the work objectives and criteria for success and recruit staff from all relevant areas of proficiency.

\subsection{Key Reasons for Project failure}

Most organizations have experienced projects that did not end on time, were over budget, or changed in scope over time. There are many pitfalls that can sink projects. Here we will focus on some basic reasons why projects fail.

\section{- $\quad$ Lack of senior management}

Senior management must prioritize requirements and make decisions. If any person is not actively involved in a project, that project is doomed for failure.

\section{- Unclear Project Objectives}

Most organizations have more opportunities and project initiatives than they can ever hope to fulfil. Many companies embark upon more initiatives than they probably should, causing over worked and often unhappy team members.

\section{- $\quad$ Scope creep}

Scope creep is a serious issue in many projects. Scope creep means an increase in what you have to deliver, without a corresponding increase in resources or an extension to the project timeline.

\section{- Gaps in communication}

Once a project is in full swing, a common issue is communication. Most project teams use email to communicate about their projects and tasks. The biggest complaint here is that project communication resides in each individual's email box. So, if a new resource joins the project, there is no centralized view of the project history.

\section{- $\quad$ Lack of visibility of all projects}

A common reason why projects fail is related to visibility. All three tiers of the project team, executive management, project managers, and team members, need access to the right level of information at the right time.

\section{SOME OF WORLD'S MAJOR PROJECT FAILURE EXAMPLES}

After analyzing these examples we will be able to come up with widespread conclusion with the lesson we learned from these project failures.

Here we are going to do in- depth case study of world's top most oil industrial market leader project failure

\subsection{Case Study: British Petroleum}

In today's dynamic and ever changing situation have forces the business organization to adopt and implement the new strategies as it is necessary to survive in the ever changing and competitive environment. In this case study we will analyse the situation of BP Oil Spill in Gulf of Mexico situated in United States of America. This oil spill results in a situation which is not only critical but also new for any oil company in the world[1]. As this deep oil spill accident was one of the worst disasters ever cost in the history of modern era. Such situation required some extremely crucial strategic management decisions. In the end we will discuss about the strategic management that can lead to a better solution of the issue.

\subsection{Background of BP}

British petroleum (BP) founded in 1909 as the Anglo-Persian oil and gas company headquartered in London England, United Kingdom. It's a sixth largest O\&G company by production and fifth largest company by annual revenue [2].Its major field of operations are exploration, production, refining, distribution and marketing of the hydrocarbon products. BP operating in over 80 countries of the world 
having over 80,000 employees. Its largest division is operating in America under the name of BP America and it's the second largest oil and gas production company in the United States. It has 22400 service stations selling about 5.9 million barrel per day [3]. It is one of those oil and gas companies who have invested heavily for the invention and adoption of new exploration technology to find petro chemical under the earth surface.

\subsection{Problem}

April 2010, in the region of Gulf of Mexico situated 52 miles southeast of the Louisiana port of Venice an explosion occurred in the Deep-Water Horizon project. This explosion cause the oil spill which was one of the worst ever oil disaster in the history of the modern world. This incident results the loss of 11 worker's lives. The fire caused the clouds of smoke covered 30 miles area while the 5 miles radius around the rig was contaminated by the spill oil [4]. The situation changed so rapidly that the well head remains open resulting in substantial amount of oil spill eliminating the aquatic life of the region with estimated death tool of 8000 animals. After many unsuccessful attempts BP was able to cap the well on 15 July stopping the oil flow.

The Deep-Water Horizon was 9 years old unit specially designed for the offshore drilling. It was a massive floating structure with the capability to operate up to the 2400 meter deep and its drilling capability was 9100 meter. The structure was manufactured by the heavy industry department of Hyundai. BP was using this semi-submersible drilling unit by leasing it from Transocean from March 2008 to September 2010.

BP took the period of three months to completely cease the oil flow into the ocean on 15th July but up to this time 4.9 million barrels of oil which is approximately equal to 780 million litres has been spilled into the ocean. During the span of three month almost 210,000 gallons of hydro chemical leaked on daily basis in Gulf Ocean. This oil spilled caused the adverse effect on the eco system which disturbed the $40 \%$ sea food supply in United States [5]. The US Government was quick to response and Obama announced $\$ 20$ billion fund as a response to cater the environmental disaster. BP also acknowledged the situation admitting that it will pay for the cleanup cost. Over 30,000 people worked across the coast to collect the oil, took primitive measures to save the lives of animals but unfortunately disaster was so critical that the effect of spill still effecting the environment [6]

\subsection{SWOT Analysis}

\section{Table 1 Swot Analysis of BP Oil Spill}

\begin{tabular}{|c|c|}
\hline $\begin{array}{l}\quad \text { STRENGTHS } \\
\text { Strong market appearance } \\
\text { Financially strong Company } \\
\text { Technological Advantage } \\
\text { Largest producer } \\
\text { Product quality } \\
\text { Brand loyalty } \\
\text { Diverse geographic experience }\end{array}$ & $\begin{array}{l}\quad \text { WEAKNESSES } \\
\text { Negative Consumer opinion } \\
\text { Poor Management }\end{array}$ \\
\hline $\begin{array}{l}\text { OPPORTUNITIES } \\
\text { Territories expansion } \\
\text { Energy alternatives } \\
\text { High quality and competitive } \\
\text { pricing }\end{array}$ & $\begin{array}{l}\text { THREATS } \\
\text { Legal threats } \\
\text { Arab spring } \\
\text { In appropriate measures } \\
\text { Limited resources }\end{array}$ \\
\hline
\end{tabular}

\subsection{Reasons for Project Failure}

- Extreme geographic location

- Weak risk management

- Lack of timely decisions

- Sluggish response in critical situation

- Undermining the situation

- $\quad$ Lack of planning

\subsection{Recommendations for British Petroleum}

- Before starting any project the employees must be trained according to their job responsibilities so that they can perform their duties correctly.

- Line manager and upper level manager must work ensure that all the quality standards must be fulfilled.

- A company must place adequate number of expert on every project who can work with skilled workers and can guide them in order for successful implementation of project.

- For any project there must be clear hierarchy so that in any critical situation the decisions must be taken as quickly as possible.

- The accuracy of all electronic equipments used in the project must be verified after periodic intervals.

- For the projects located in remote areas the must be some fast transport resources that can be used in case of emergency so minimize the loss of life of employees.

- Organization must develop a culture where employees can understand their responsibilities and the potential risk of making wrong decision.

- Main causes of project failure are mostly due to difficulty in performing the critical task so proper standard operating procedure (SOP) must be defined for such tasks.

\section{CASE STUDY: CHRYSLER AND FIAT}

This case study is about automobile companies. Details are described below.

\subsection{Background of case}

Chrysler and Fiat are auto-mobile companies. Chrysler's best assets were its Jeeps, minivans, and light trucks. Fiat's expertise was in small car technology and fuel-efficient engines, the very thing that Chrysler lacked.

Chrysler merged with fiat on June 10, 2009. Marchionne became CEO of the company. In 1998 Chrysler merged with Dailmer-Ben. But this merger was not successful one. In 2007 Daimler sold Chrysler to Cerberus, a private equity firm but again Cerberus was not able to save company from failure.[7]

In the past Fiat was at loss and Marchionne was the one who saved the company from failure. Now here we will find out what changes a company has to face while merger? How the leader handle these challenges? 


\subsection{Organizational Change}

Organization change refers to managing different changing aspect of the organization such as physical environment, introducing new technology, alteration in mission, business process and policies, change in management team, merger, reengineering etc. When the change is significant and primary experts call it organizational transformation.[8]

\subsubsection{Causes of organizational change}

Companies face numerous situations during the process of change which leads to anxiety and ambiguity. In order to become a prosperous organization, it is imperative for the companies to incorporate upgraded technologies for producing goods, innovative products to be introduced which are anticipated by the market, modern methods of administration must be executed along with improvement in the expertise of the workers.[9] Companies must be capable of coping with all dimensions related to the reforms. The companies who get accustomed to change are able to boost their revenues and being appreciated as well.

The management must be competent to deal with all the aspects which influence their companies. Alterations in the companies are driven by the following internal and external elements prevailing in the environment;

- Political, technical, economical and societal enticements prevailing in the outer environment of the company can bring change in the external environment.

- On the other hand, the policies, styles, systems and procedures adopted by the company's management along with the behaviour of the workers influence the internal environment.

\subsection{Merger as a part of organizational change \\ 4.3.1 Merger}

A merger is a combination of two companies to create a new single company.

\subsubsection{Reasons for merger}

There are numerous reasons for companies to merge. Mergers provides firm with facility to maintain their market position. It also provides facilities to companies to combine itself with other to strengthen itself and work more effectively and efficiently. Company can progress by using new technologies and innovation and using resources of successful Company. There is no guarantee that merger will be successful. [10]

\subsubsection{Cultural Aspect of merger}

Culture plays vital role in merger and it can be reason of failure or success of merger. Fiat and Chrysler merger was a cross-border merger so we will look at cultural aspects of merger with respect to two different countries.

\subsubsection{Cross-Border Merger}

Cross-border merger is combination of two companies of two different countries. Cross-border M\&A is defined as an activity in which an enterprise from one country buys the whole asset or controlling percentage of an enterprise in another country. [11]

\subsection{Corporate Culture}

Corporate culture is the building block of an organization. It's combination of shared values, beliefs and behavior of the group. It's a way through which things are performed in organization. Corporate culture is shared by the leader and gives its people the direction to move towards achieving company's goal.[12]

\subsubsection{Cultural Differences between Chrysler and Fiat}

Fiat was an Italian company and Chrysler was American. After merger the company faced culture difference described below:

Table 2: Difference between American and Italian Corporate Culture ${ }^{[13]}$

\begin{tabular}{|c|c|}
\hline American Corporate Culture & Italian Corporate Culture \\
\hline 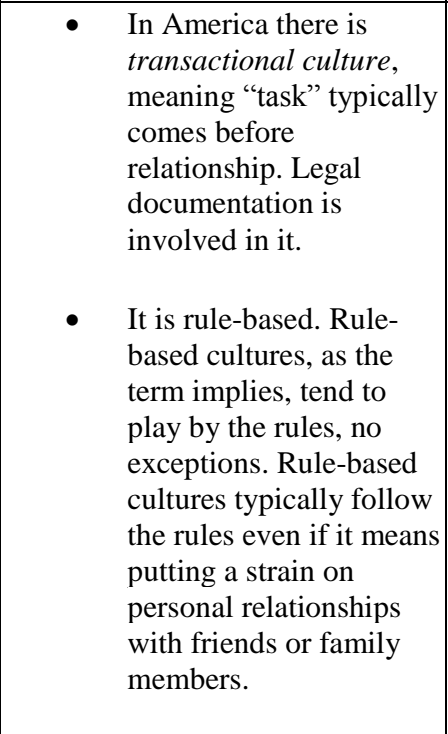 & 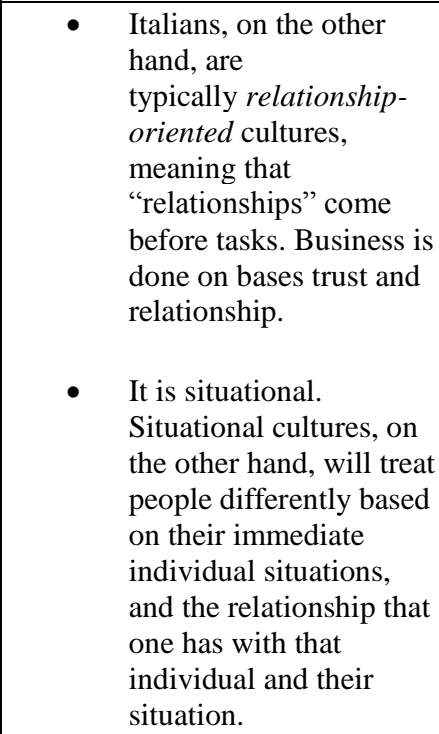 \\
\hline $\begin{array}{l}\text { - Americans tend to } \\
\text { be low-context } \\
\text { communicators, } \\
\text { meaning they tend to } \\
\text { value saying exactly } \\
\text { what they mean. }\end{array}$ & $\begin{array}{l}\text { Italians tend to be high- } \\
\text { context communicators, } \\
\text { meaning they do not } \\
\text { typically express ideas. } \\
\text { Thus, create ambiguity. }\end{array}$ \\
\hline
\end{tabular}

Keeping view the dissimilarities between Italians and USAmericans, it can be judged that these dissimilarities will pose issues for all the stakeholders since such dissimilarities make themselves evident in every phase of the day to day work liaison ranging from management of project, planning of meeting to tactical planning . The purpose is to maintain the influence of cultural dissimilarities in order to lessen the errors and misinterpretations at the time of enhancement of essential benefits. The only way to achieve success is to offer adequate training in order to acquaint the leadership, employees and management with various cultures so that all can work in harmony.

\subsection{Managing organizational change and cultural difference}

From above information its clear that organization culture and organizational change are inter-related. While merger organizational change takes place and in our case study it's mentioned that after merge the CEO of the company changed now he has to manage the change and develop a corporate 
culture which will be suitable for employees. Although accepting change for an employee is very difficult. Mostly employees are reluctant to change. Now we will find out how change can be implemented and what strategies can be used to manage it so that it can be beneficial for the company.

Change is not one-time occurrence but it is ongoing reality. Effective change management is part of larger workforce management, which focuses on improving overall performance of business to accomplish desired goals. It's the responsibility of the top leader to bring an effective process and awareness of effective behavior change throughout the organization.[14]

Furthermore, the leaders have the responsibility of inducing willingness in the workers to acknowledge the change throughout the organization.

- Senior leaders have the duty to commence, advice, and support the process of change. They must assure that all the workers have the complete know-how of the process of change throughout the company. They must also ensure accomplishment of the activities and develop suitable reactions to change.

- Middle managers are responsible for assisting the change and guiding their workers to comprehend the motives behind the change and how to become accustomed to this change.

- Employees have no role in making the choice on change that is why they might require guidance to develop policies to deal with the expected confrontation towards change. It is possible through workshops, evaluations and group discussions. Moreover, the workers must comprehend the motives behind the change, their part and how they can add to the procedure.

The leaders must make sure that the workers have defined roles and accountabilities along with the authority so that they could induce required variations in the tasks assigned to them.

\section{CASE STUDY: THE MILLENNIUM DOME}

Third case study is about millennium dome. Given below is the brief history about this dome.

\subsection{About Millennium Dome}

Millennium Dome is a Dome shaped mega structure, built in the Greenwich peninsula in south east London. It was designed for the celebration purpose at the time of third Millennium. Third millennium is a time period from January 1, 2001 to end of December 31, 3000.

At the time of construction it was considered as the mega structure in the world with respect to its size the Dome has a theme park and a scientific exhibition both which is entitled as the Millennium experience.

The Millennium Dome closed on 31st of December 2000 because it failed to attract the number of visitors which was expected to visit the place and results in many financial problems. As a result the Dome has been sold and converted into a sports arena. [15]

\subsection{Background of the case}

It was an achievement for opening a Millennium Dome on time. Initially this Dome attract a number of paying visitors but eventually this number decreases so much that it beaten the record of visitors in 1999 in England. This Millennium Dome is a fully funded project and it has been funded by three sources that is national lottery, visitors and sponsors.

During its operational year the company has faced many financial problems. One reason is of decrease in the number of visitors. In order to deal with these financial problems company has done a number of changes at senior levels, like in year 2000 the company's chief executive, finance director and accounting officers were replaced with new ones.

The company's solvency issue was a matter of concern throughout the year and it was solved at the end. [16]

\subsection{Reasons for failure}

- Lack of vision: The project was not properly planed; they were unclear with the scope of the project. The original plan was to transform the Millennium Dome into a soccer pitch for use of one the teams of London but in the end none of the teams seems interested. At the end the British Government decided to find the appropriate buyer because the cost of maintenance was too high, it was reported to be $£ 1 \mathrm{M}$ per month. ${ }^{[17]}$

- Poor execution: poor execution cause lacklustre content resulting in negative experiences for visitors and the resulting negative PR stemming for those experiences.

- Criticisms: Initial reaction from the press was poor. Lack of content, themes and creativity were the common factors of criticism.

- Lack of sufficient operational expertise: The Company lacked sufficient operational expertise. Running such a major attraction called for specific operational expertise quite distinct from that required to construct the Dome.

- Poor marketing strategies: Marketing and sales strategies were based on the Dome selling itself. Poor marketing results in shortfall of sales tickets. The company's marketing budget in the business plan was originally set very low as compared to the large visitor attractions. As there were no competitors so the company's estimations about building a good reputation only with word of mouth and sales tickets was not enough to attract the new visitors.

- Financially mismanaged project: It was financially a mismanaged project which was failed to attract new visitors. Throughout the planning and construction phase the cost raises which results in more and more dispersion of money to dome's builders. ${ }^{[18]}$

- Lack of contingency plan: Due to lack of contingency plan they were failed to manage expectations.

\subsection{Recommendations for Millennium Dome}

Millennium Dome is a unique project. Following recommendations with respect to Project management are given below. 


\subsubsection{Management structure}

- Management structure includes that the entire project related tasks are properly defined, who reports to whom, what interaction patterns should be followed. What is the communication style, motivational techniques for employees.

- Project manager's answerability and responsibility related to project should be clear, focused and straightforward.

- Organizational structure and management's ability should integrate to meet the requirements of the project that is to plan, build, run and close.

\subsubsection{Project costs}

- The projects should only proceed if they are clear with full life cycle assessment cost of the project.

- Risk analysis of the project is necessary so that a project manager should understand the cost which could arise in the later stages of the project and prepare a plan for it.

\subsubsection{Project income}

- Project planning the most important phase in the life cycle of the project. Resources like time and money is used at this time. Projects like in Millennium Dome where the success of the project depends on the number of visitors, the project manager keep in mind the uncertainties related this type of income. This can only be done with the help of careful and practical assumptions.

- to make realistic decisions about likely visitor numbers, and put in place effective marketing, the timetable needs to allow for a reasonable period for the development of a clear vision of what the product is and a fully thought through pricing strategy.[19]

- While working with financial sponsors like in this case of millennium dome it was funded by three sources so project manager working with financial partners must estimated the risk associated with financial contribution and discuss it in the project planning phase.[20]

\subsubsection{Contingency planning}

- If plan A does not work or there may be any changes so plan B should always be there to help the project to run smoothly.

- Projects which depend largely on trading income , and when there is risk attach to that income, it is important to be flexible at time of responding if the trading positions become worse.

- Managers find it difficult to respond at times when there are situations which were not easily predictable unless and until they have already developed a crises plan or contingency plan at the time of project planning phase.[21]

\subsubsection{Financial management}

- All expenditure commitments such as expenditures that a company has committed to spend over a period of time in a project should be recorded on central tracking system so that all the invoices received against that commitment should be recorded properly. This will help you to identify all the expenditures and total liability at any time when needed to check the financial position of the project.[22]

\section{CONCLUSION}

With the help of three different case studies of projects failure we have come to a conclusion that project failure is preventable with good project planning. When a project starts to fail there are techniques to recognize and trained Project managers minimize the extend of project failure or recover the failed projects as early as possible. So project manager needs to be trained in such techniques so that he/she not only recover the failed projects but also reduce the chances of failure. By following these techniques as discussed in the document you will enhance project's chance of success.

\section{REFERENCES}

[1] Achenbach, J, BP's cost cuts contributed to oil spill disaster, federal probe finds. The Washington Post2011, September 14. http://articles.washingtonpost.com/201109-14/national/35273061_1_transocean-macondodeepwater-horizon

[2] Goldenburg, S, BP oil spill blamed on management and communications failures, The Guardian, 2010, December 2.h ttp://www.guardian.co.uk/business/2010/dec/02/bpoil-spill-failures

[3] Shankleman, J, BP oil spill caused by management failure, says White House commission, 2011, January 6.

[4] Sandman, P, Risk communication lessons learned from the BP oil spill, 2010, September 13 http://www.psandman.com/col/deepwater4.htm

[5] Wearden, G, BP oil spill costs hit \$40bn, 2010, November 2, Retrieved February 3, 2013. http://www.guardian.co.uk/business/2010/nov/02/bp-oilspill-costs-40-billion-dollars

[6] Beard. E., Hannan, M,. \& Hayward, P, After the Spill. (Cover Story). Parksand Recreation, Pg 38-45, 2010

[7] Barry Shore "Project Failures From the Top Down: Can Marchionne Save Chrysler" project smart,2009,June18.

[8] Carter McNamara "Basic context for organization change". http://managementhelp.org/organizationalchange/basics. htm

[9] Cliff Notes,"Causes of organization change". http://www.cliffsnotes.com/more-subjects/principles-ofmanagement/managing-change/causes-of-organizationalchange

[10] Randall S. Schuler and Susan E. Jackson "HR issues, activities and responsibilities in mergers and acquisitions" School of Management and Labour Relations, Rutgers University New Brunswick, NJ, USA.

[11] Rong Zhang "Cultural Integration in Cross-Border Mergers \&Acquisitions" University of Twente, 2010, November 11.

[12] Joanne Mowat," Corporate Culture", The Herridge Group.

[13] Nicole Barile,Chrysler \& Fiat: Understanding Intercultural Differences ,Challenge for Cross-Border Business? Global business mobile talent. 
[14] Deborah Schroeder-Saulnier "Organizational Effectiveness" Responding to Change With Agility: The Leader's Role

[15] Long span structures Architecture Week, 26 March 2003

[16] Hellman, Louis (26 June 1997). "Letter: Millennium Tent". Letters to The Independent. Retrieved 29 June 2009.

[17] "House of Commons Hansard Debates 13 November 2000". Commons Hansard Debates. 13 November 2000. Retrieved 29 June 2009.
[18] "Stephen Bayley on the rebirth of the Millennium Dome". The Observer. 24 June 2007. Retrieved 29 June 2009.

[19] Sir John, 2000 National Audit Office report, 9 November 2000

[20] "Four Documentaries - Abroad Again in Britain". BBC. Retrieved 10 August 2011.

[21] "Dome woes haunt Blair". BBC News. 15 February 2001. Retrieved 31 January 2007

[22] Paul Mitchell. "World Socialist Web Site." (27 June 2000). Why London's Millennium Dome Has Been a Disaster 